\title{
Net Benefit Assessment of Illustrative Climate Adaptation Policy for Built Assets
}

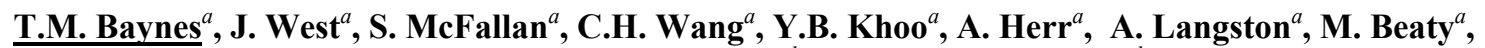 \\ Y. Li ${ }^{a}$, K.W. Lau ${ }^{a}$, S. Mazouz ${ }^{c}$, G. Quezada ${ }^{a}$, X. Wang ${ }^{b}$, Mark Stafford-Smith $^{b}$ and S. Hatfield-Dodds ${ }^{b}$ \\ ${ }^{a}$ Ecosystems Sciences Division, Commonwealth Scientific and Industrial Research Organization \\ ${ }^{b}$ Climate Adaptation Flagship, Commonwealth Scientific and Industrial Research Organization \\ ${ }^{c}$ EcoPerspectives Pty Ltd \\ Email:Tim.Baynes@,csiro.au
}

\begin{abstract}
We report on the modeling and initial results from the first national-scale integrated assessment of costs and benefits of different climate adaptation policy approaches affecting built assets at statistical local area resolution. In this study we simulated damage incurred from coastal inundation hazard under three climate outlooks. At all stages, from inception to review of results, our key stakeholders were involved notably as sources of policy innovation, and as guides to the logic of policy action; enabling codification of climate adaptation responses according to stylized policy stances. These stances represented different levels of caution and different approaches to implementing three general adaptation actions: avoidance, accommodation and protection. The performance of each stance was defined by the benefit of avoided damage costs compared to the cost of climate adaptation action measured in net present value terms. Absolute measures of policy merit have been averted because of the epistemic uncertainty in the modeling of such a multi-dimensional space over a national scale, combined with considerable variance in climate inputs. Therefore, performance of policy stances, under each of the climate outlooks, is presented relative to a nonadaptive case that continues the use of current construction standards and approaches to climate adaptation. This comparison of relative merit provides new insight to inform policy-making and contributes to the development of adaptation science.
\end{abstract}

Keywords: Climate adaptation, policy simulation, coastal inundation 


\section{INTRODUCTION}

While there is some certainty that the future will contain a changed climate from that we enjoy today (IPCC 2007), there is considerable uncertainty surrounding the future impact of climate. The important question of what to do about potential future impact is a complex and contested policy space (Australian Greenhouse Office 2006; Department of Climate Change 2009; Department of Climate Change and Energy Efficiency 2010; Productivity Commision 2012)

Previous assessments of climate change impact in Australia have focused on exposure or impact alone (Department of Climate Change 2009; Baynes et al. 2012) or performed detailed analysis at local scales (McInnes et al. 2007; McInnes et al. 2009; Fletcher et al. 2013). The detailed hydrological and/or economic modeling effort needed in those cases was not feasible for our purposes for the following reasons.

The overall project, within which this work is situated, attempts the difficult task of assessing four different types of climate change impacts, as they affect three different development scenarios, subject to three climate outlooks, at the national scale but with local resolution $\sim 1400$ statistical local areas (SLA) as at 2006.

This difficulty is magnified by representing an active stakeholder in the simulation that responds to future climate impacts with any one of three stylized policy approaches each of which allows for three possible adaptation actions. The control and understanding of the permutations of the simulated outcomes alone requires some thinking. To manage complexity and have some tractability in this multi-dimensional simulation, our approach was one of overlaying information, akin to a GIS analysis but with a model of policy action involving minimal feedbacks.

At all stages, from inception to review of results, our key stakeholders were involved, notably as sources of policy innovation, and as guides to the logic of policy action; enabling codification of climate adaptation responses according to stylized policy stances. These stances represented different levels of caution and different approaches to implementing three general adaptation actions: avoidance, accommodation and protection

This research offers an evidence-based exploration of the potential costs and benefits of anticipatory (projections based) and reactive (observation based) policy stances for managing climate risks faced by Australia's built assets. Specifically, the project terms of reference set out two primary aims:

- To demonstrate practical methods for comparing the costs and benefits of different policy options for adapting to climate change impacts under a range of possible futures.

- To explore the robustness of selected adaptation policy stances under different climate and development scenarios assessed with a range of time-discounting factors.

\section{MODEL AND FLOW OF INFORMATION}

Compound scenarios were built up from climate outlooks [1.1] and development scenarios [1.2] and the policy stances [1.3] were implemented through enacting one of three adaptation responses [1.4] - refer to Figure 1. Policy stances [1.3] shaped investments required to meet adaptation demand (if any) in each simulated annual time step, informed by exposure to coastal inundation hazard (and, in other work, floodplains, extreme wind and fire hazard).

Differences in adaptation capital expenditures [1.5] occur through the choice of specified response options [1.4]: perimeter defense against inundation and flooding ('protect'); higher design standards ('accommodate'), and; variations in micro-location ('avoid'). For coastal inundation, 'avoid' involved locating new or replacement assets to elevations at least equal to that of a 1 in 100 year event.

Together, these are intended to reduce the exposure and vulnerability of built assets within a region. Climate outlooks [1.1 are used to generate regionally detailed climate hazard maps [2.1], which in turn are used to generate estimates of direct damages - if any - for each region and annual time step [2.2]. This is based on exposure, vulnerability and design standard of built assets for each annual time step.

In the only feedback of the model, damage loss may result in adaptation investment to install defenses, replace damaged assets or institute improved standards, any of which may reduce future direct damages. Projected likely damage costs [2.2] are estimated at $T$, in the Anticipate stance, and at $t$ in all other stances. T he scenario modeling process [2.3] codes the policy stances and generates a detailed set of scenarios, each detailing a national portfolio of built assets. This process produces estimates of total annual capital expenditures [2.4] and climate related capital losses [2.2] accounting for potential coastal inundation hazard now and in the future. 
The estimates of capital expenditure and climate damages provide the basis for an economic analysis [3.1] of the costs and benefits of the different illustrative policy stances. The scope of the analysis focuses on relative differences in direct capital costs and associated avoided capital losses over the life of the built assets. It is expected that policy stances will perform differently across climate outlooks (and, in further work, types of hazard). Replacement capital costs were chosen deliberately for this analysis because estimates are less controversial and, aside from the size of the task, controversy over estimation methods and data availability for the full set of impacts could detract from the conclusions.

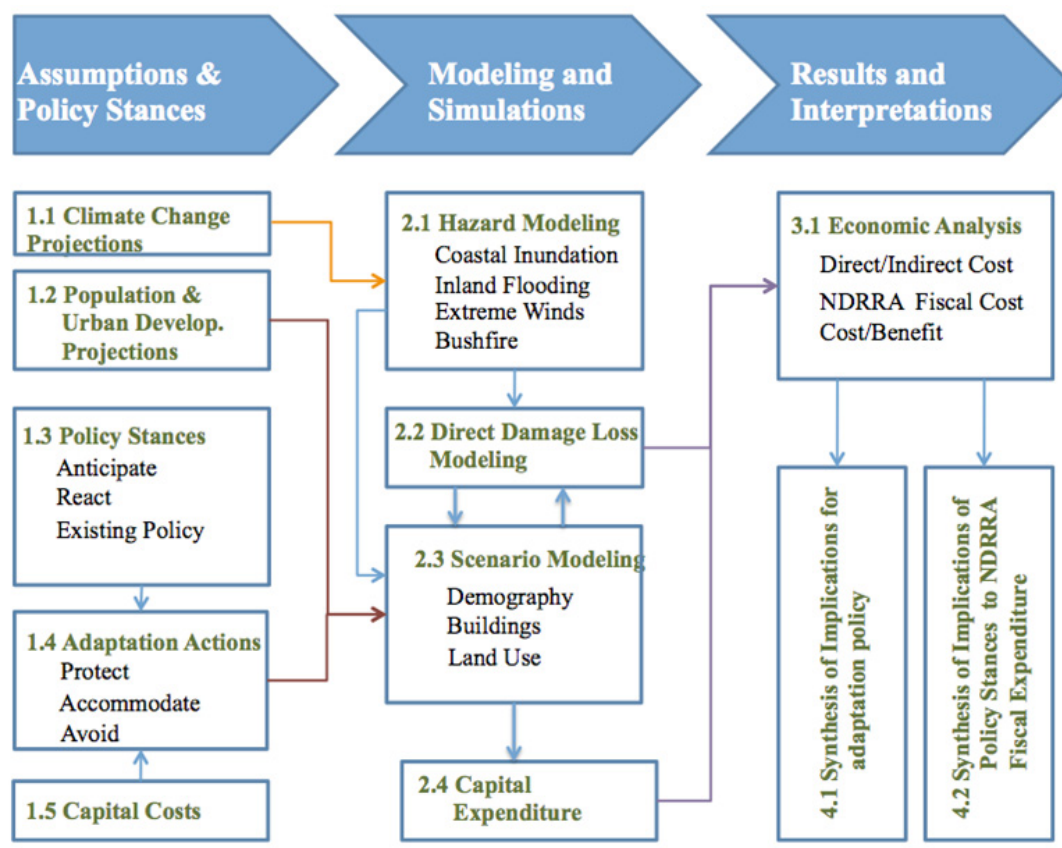

Figure 1: Project flowchart

This means that the modeling underestimates the impact of climate events, leaving out other highly relevant costs such as interruption to business activity, clean up and rebuilding phases as well as lives lost, injuries, dislocation etc.

\section{INPUT DATA AND ASSUMPTIONS}

The three most important inputs to this modeling exercise were the spatially specific, time-series data sets on coastal inundation hazard and the velocity stage-damage functions; the future distribution of development and; the codified concepts and definitions of the policy responses. Within these areas there are a number of parameters summarized in Table 1.

We used the $5^{\text {th }}, 50^{\text {th }}$ and $95^{\text {th }}$ percentile sea-level rise (SLR) projections from IPCC AR4 allowing for ice sheet discharge (Church et al. 2008) applied to the B1, A1B, and A1FI outlook scenarios respectively. This is a range of $0.18 \mathrm{~m}$ to $0.79 \mathrm{~m}$ by 2100 (see Figure

2). We looked at regional deviation from the global mean based on 17 climate model simulations for the A1B scenario, and CMAR (2012) was able to give the averaged projections of SLR for 2030 and 2070 around the $14,000 \mathrm{~km}$ Australian coastline. The maximum projected regional variation is about $15 \%$ of the mean global SLR by the B1 scenario, and $11 \%$ of that by the A1FI scenario. The local deviation was not found to have a significant effect on storm tides.

Figure 2: Mean global seal level rise (meters: $\mathrm{m}$ ) for the B1, A1B, and A1FI emissions scenarios

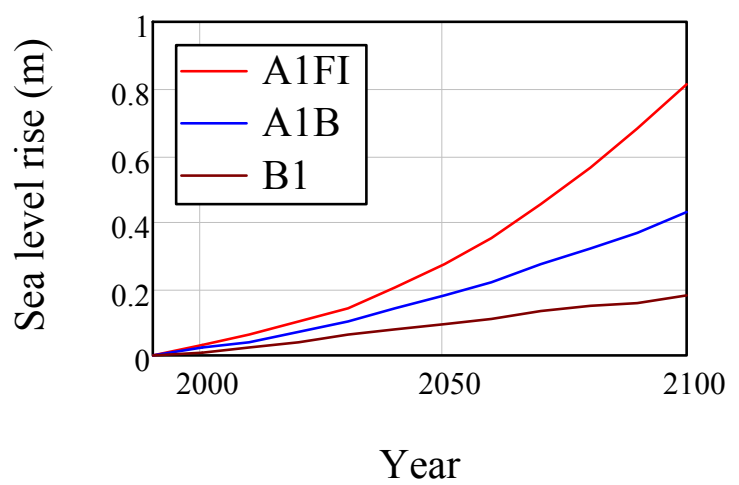

Flood velocity stage-damage functions relating damage to the fraction of a house inundated and the velocity of the floodwaters were provided by Geoscience Australia (Middelmann-Fernandes 2010). The height and impact of a coastal storm surge depends on the local topography. The topography was captured in part by the ground height estimates derived from the SRTM 1-sec. digital elevation model (DEM) (GA 2009). This data used EGM96 as a reference height. Asset location data from the G-NAF database was combined with the DEM data to provide initial locations and asset elevation throughout Australia. Within SLA boundaries we did not attempt to model more spatially precise development and the fraction of future assets exposed was 
estimated to be the same as the initial conditions in a given SLA. This was subject to change by any adaptation action.

The scenarios of development were scaled to that of population distribution which initially used SLA-level projections $^{2}$ to 2027 . Thereafter population distribution was simulated three ways while adhering to ABS state- and national- level projections to 2100 (ABS 2008). For the Business as Usual (BAU) scenario SLAs were filled pro rata according to their population at 2027 until their residential density increased to the next highest density decile ${ }^{1}$. Any overspill was delivered to remaining unfilled SLAs. Urban Consolidation (UC) proceeded as for BAU with only an upper density limit of 1000persons/ha. Regional Development (RD) placed some 10 million of Australia's future 45 million people (at 2100) in regional inland centres designated by their rank order of total resident population at the 2006 census.

Table 1: summary of inputs and assumptions in the policy-modeling task.

\begin{tabular}{|c|c|c|}
\hline & Range or types & Source of information \\
\hline Spatial detail & $\begin{array}{l}2006 \text { SLA boundaries } \\
\text { for all of Australia } \\
\text { grouped by coastal } \\
\text { flood basins }\end{array}$ & $\begin{array}{l}\text { ABS Cat1259.0.30.001 ASGC Digital } \\
\text { Boundaries Australia, 2007, digital elevation } \\
\text { data supplied by Geoscience Australia }\end{array}$ \\
\hline Simulation Time scale & $\begin{array}{l}2006 \text { to } 2100 \text { in annual } \\
\text { steps }\end{array}$ & Not Applicable \\
\hline Climate Outlooks & $\begin{array}{l}\text { Historical climate } \\
\text { record up to } 2006 \text { and } \\
\text { the A1B, A1FI and B1 } \\
\text { SRES climate scenarios }\end{array}$ & $\begin{array}{l}\text { Scenario definitions are presented by IPCC } \\
(2000) \text { and SLR is from the IPCC } 4^{\text {th }} \\
\text { Assessment allowing for ice-sheet discharge }\end{array}$ \\
\hline Development Scenarios & $\begin{array}{l}\text { Business as Usual, } \\
\text { Urban Consolidation, } \\
\text { Regional Development }\end{array}$ & $\begin{array}{l}\text { Based on the existing location of assets and } \\
\text { SLA-level projections from the Australian } \\
\text { Department of Health and Aging }{ }^{2} \text {. Refined by } \\
\text { discussion with stakeholder }\end{array}$ \\
\hline $\begin{array}{l}\text { Velocity stage - damage } \\
\text { functions }\end{array}$ & $\begin{array}{l}\text { Four dwelling types } \\
\text { based on wall and roof } \\
\text { construction. }\end{array}$ & Geoscience Australia \\
\hline Policy Stances & $\begin{array}{l}\text { Current Policies, React, } \\
\text { Anticipate }\end{array}$ & Defined by stakeholder \\
\hline Adaptation Actions & $\begin{array}{l}\text { Avoid, Accommodate, } \\
\text { Protect }\end{array}$ & Defined by stakeholder \\
\hline Current asset location & Not Applicable & $\begin{array}{l}\text { Geocoded Australian addresses from the G- } \\
\text { NAF database see: } \\
\text { www.psma.com.au/?product=g-naf }\end{array}$ \\
\hline $\begin{array}{c}2006 \text { asset replacement } \\
\text { values }\end{array}$ & $\begin{array}{l}\text { Approximate national } \\
\text { average of } \$ 350,000\end{array}$ & $\begin{array}{l}\text { Derived from information in the NEXIS } \\
\text { database }\end{array}$ \\
\hline Time Discount Rates & $1.3 \%, 2.6 \%$ and $4 \%$ & Garnaut (2008) \\
\hline
\end{tabular}

Our three stylized policy stances were developed in iterative consultations with stakeholders in national climate adaptation policy. These can be summarized as follows:

Current Policies: Act in line with 2012 practices, policies and climate information. A number of current state-level policies have planning provisions for flood that refer to $1 / 100$ year events based on historical data.

React: This stance acts on the simulated climate trends and hazards up to some time, $t$, or 'what has happened', based on observed outcomes at the location and other similar areas (as simulated up to that year). This allows for expected damage costs to actually be incurred before adaptation is initiated.

\footnotetext{
1 decile categories derived from densities on all residential census meshblocks for Australia in 2006

2 www.health.gov.au/internet/main/publishing.nsf/Content/ageing-stats-lapp.htm
} 
Anticipate: This stance looks forward and acts at some time, $t$, on the expected value of hazard levels at a future time point $T=(t+$ asset life $)$ or 2100 whichever is the earlier date. The magnitude of the investment in adaptation is based on the expected magnitude of a design standard event (e.g. 1/100 ARI storm tide event) at time, $T$, in the A1B climate outlook.

For the sake of clarity, a combination of the above features was designated the 'central case', which entailed the A1B climate outlook, the BAU development scenario and a $2.6 \%$ discount rate. Each stance/adaptation action was initially simulated for this central case. Then, other, more extreme combinations were explored as a sensitivity analysis. The performance of the above stances were compared with a non-adaptive 'Reference Case' in which assets were assumed to be built, damaged and replaced, like-for-like, despite climate impacts.

\section{RESULTS}

There are a large number of different possible results to present. Here we present the initial results on coastal inundation for the 'central case' mentioned earlier. Aggregate costs up to 2100 are presented in net present value terms discounted back to 2006 (NPV \$2006). In Figure 3 and 4 the $5^{\text {th }}$ and $95^{\text {th }}$ percentiles are shown for the 100 model runs that simulated future storm-tide events.

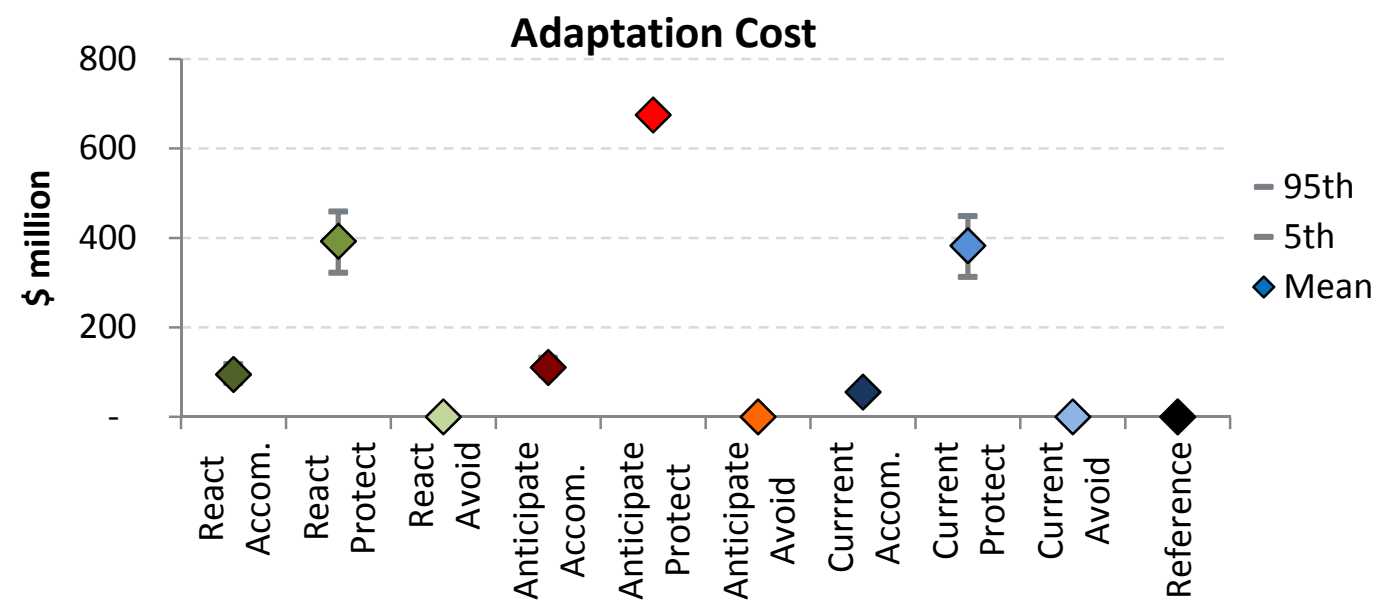

Figure 3: NPV of adaptation costs by policy stance and adaptation option

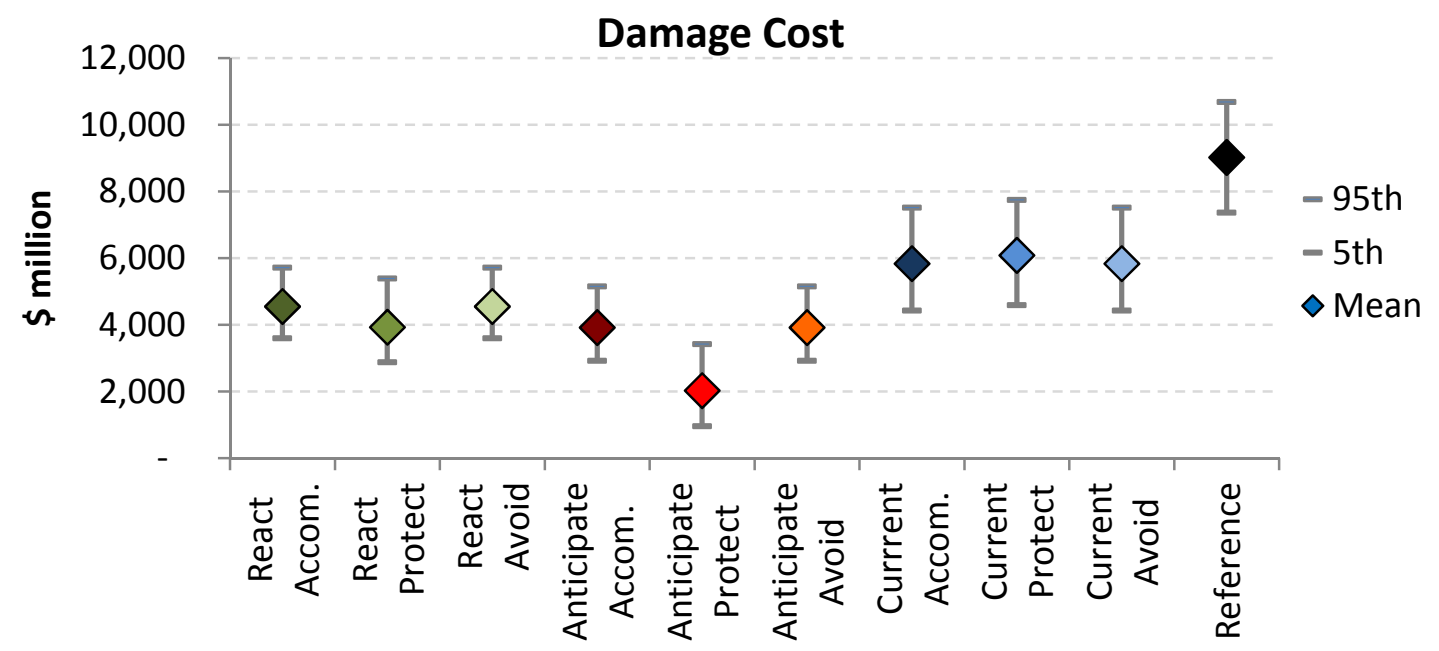

Figure 4: NPV of damage costs by policy stance and adaptation options

The 'avoid' adaptation, under all stances was assumed to add zero structural cost. The per-unit costs of seawalls for protection was obtained from Fletcher et al (2013) and, in total, this is the most expensive action. Accommodation action costs were derived from industry quotes for building new houses at different levels of elevation. Whereas protective action bears the cost of defending all existing and new assets, accommodation only deals in the extra cost of upgrading standards in new or replacement dwellings. In all policy stance/action combinations, the cost of adaptation is an order of magnitude less than that of damages, even 
for the generally more expensive 'protect' adaptation option. Across policy stances, the mean damage costs (Figure 4) are lowest for the Anticipatory stance but the results for 'accommodation' and 'avoid' actions are within the same range as for the React stance. There are generally less damages incurred by React or Anticipate stances than the Current Policy stance.

In Figure 5 we calculated the net benefit $=$ damage avoided compared to the Reference Case minus adaptation costs, further exploring the robustness of results to high and low climate outlooks with low and high discount rates respectively.

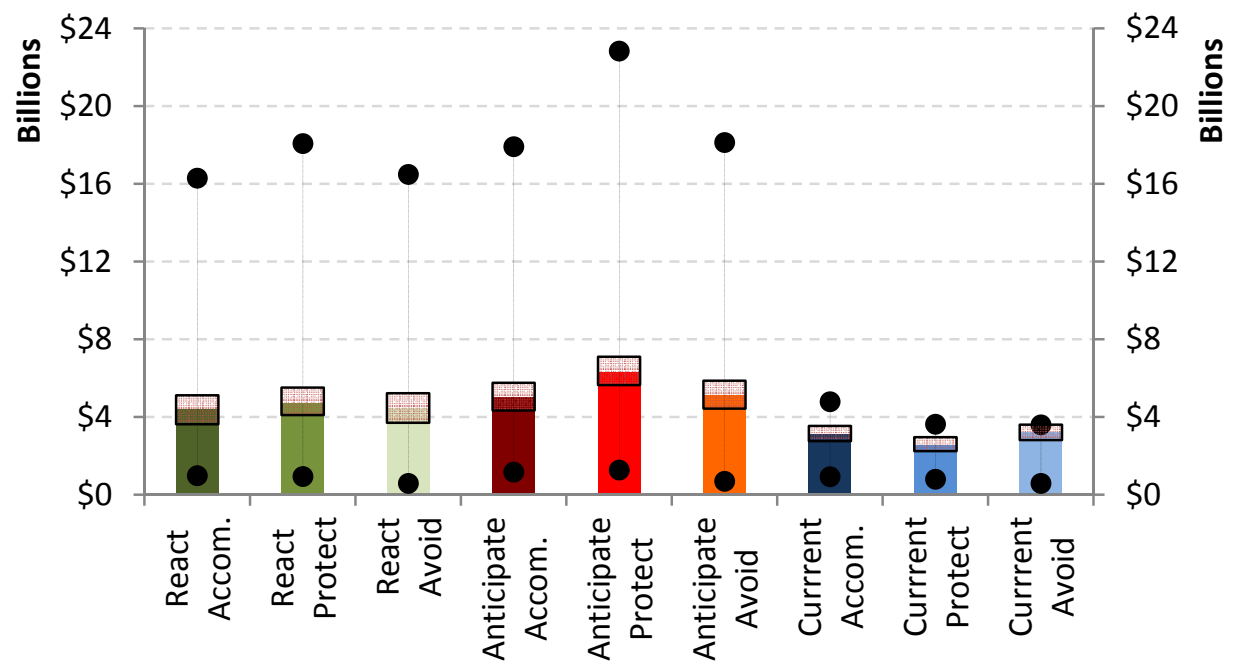

Figure 5: Net benefit of different policy stances according to the central case (columns) showing $5^{\text {th }}$ and $95^{\text {th }}$ percentiles of climate variation in modeling (pink rectangles), the 'lowest damage' B1 climate outlook combined with a $4 \%$ discount rate (lower dots) and the 'highest damage' A1FI climate outlook combined with a $1.3 \%$ discount rate (higher dots)

Across the range of climate outlooks and time discount rates explored, we found general pattern in the rank order of stances' net benefit performance was retained. Clearly there is some difference in magnitude between the central case (coloured columns in Figure 5) and the extremes of the scenario sensitivity analysis, but two general insights can be gleaned:

- For the extreme combination of minimum damage likelihood and minimum valuation, that produces low values of net benefit, all the values are positive. Even in the most benign climate future with a high time preference discount rate (lower points in Figure 5), there are no stances that have adaption costs greater than the damage avoided because of those adaptations.

- For the extreme combination that involves the maximum damage likelihood and calculates any damage with the maximum valuation (upper points in Figure 5), the 'Current' policy results do not shift as significantly as the Anticipate and React stance results. This indicates that it is worth more, in net benefit terms, to adapt and avert the damage of a more extreme climate outlook but this is most effectively achieved if we enact policies that take notice of climate change.

\section{CONCLUSIONS}

Assessments of climate adaptation options must go beyond analysis of exposure and vulnerability to explore how exposure and vulnerability to climate impacts can be shaped by alternative stances towards management responses, and how these stances perform across different potential climate outcomes over time. In-depth integrated assessments of adaptation options have been conducted for specific locations, such as the City of London (Dawson et al. 2009). However, we are not aware of any continental scale assessment that has been undertaken for buildings across all major climate hazards involving capital damages.

The current project is a technically ambitious contribution to adaptation science and the evidence base for the development of Australian adaptation policy options. It involves the simulation of the quantity, location, impact on, and adaptation of, a large number of built assets.

The costs and benefits of several stylized policy stances have been calculated, based on estimated total capital expenditures and likely damage losses across different policy stances and hazards associated with climate change. 
The modeling underestimates impacts because it does not account for indirect economic impacts or joint events (e.g. damage from flood and wind combined in a single storm event) whereas adaptation action could be triggered on the basis of total damage from disaster events that combine different hazards. The estimates provided can therefore provide insights into the direction of effects, not their actual magnitude.

Initial results suggest that generally investment in adaptation measures has payoffs one order of magnitude greater than the cost of adaptation and specifically, anticipatory actions have a greater net benefit than either a policy reacting to climate change as it happens or one that simply maintains current standards. In the case of an extreme climate outlook, there is a significant net benefit to policy stances that respond to recent climate history compared to policies that base their standards on climate data up to 2006.

\section{ACKNOWLEDGEMENTS}

This work has been supported by the Australian Department of Climate Change and Energy Efficiency and CSIRO's Climate Adaptation Flagship. We are also grateful to Geoscience Australia for the provision of stage-damage functions, other data and advice.

\section{REFERENCES}

ABS (2008). Population Projections, Australia, 2006 to 2101 (ABS 32220). In: (ed. Statistics ABo) Canberra, Australia.

Australian Greenhouse Office (2006). Climate Change Impacts and Risk Management - A Guide for Business and Government. Australian Government Department of the Environment and Heritage, Canberra.

Baynes T.M., Herr A., Langston A. \& Schandl H. (2012). Coastal Climate Risk Project Milestone 1 Final Report to the Australian Department of Climate Change and Energy Efficiency. In. CSIRO Climate Adaptation Flagship Canberra, Australia, p. 104.

Church J.A., White N.J., Hunter J.R. \& Lumbeck K. (2008). Briefing: A post-IPCC AR4 update on sea-level rise. In. Antarctic Climate and Ecosystems Cooperative Research Centre Hobart, Australia.

CMAR (2012). Sea level rise: IPCC AR4 Sea-Level Projections - An Update

Department of Climate Change (2009). Climate Change Risks to Australia's Coast: A First Pass National Assessment, Canberra, ACT.

Department of Climate Change and Energy Efficiency (2010). Climate Change Adaptation Actions for Local Governments. Department of Climate Change and Energy Efficiency, Canberra.

Fletcher C.S., Taylor B.M., Rambaldi A.N., Harman B.P., Heyenga S., Ganegodage K.R., Lipkin F. \& McAllister R.R.J. (2013). Costs and coasts: an empirical assessment of physical and institutional climate adaptation pathways. In. National Climate Change Adaptation Research Facility Gold Coast, p. 59.

Garnaut R. (2008). The Garnaut Climate Change Review, Final Report. In: Cambridge University Press, Cambridge, UK and Melbourne, Australia.

IPCC (2000). Emissions Scenarios, Summary for Policy Makers. A Special Report of IPCC Working Group III. In. Intergovernmental Panel on Climate Change Cambridge, UK and New York, USA.

IPCC (2007). Climate Change 2007: Synthesis Report. Contribution of Working Groups I, II and III to the Fourth Assessment Report of the Intergovernmental Panel on Climate Change. In: (ed. [Core Writing Team P, R.K and Reisinger, A. (eds.)]). Intergovernmental Panel on Climate Change Geneva, Switzerland, p. 104.

McInnes K.L., Abbs D.A., O'Farrell S.P., Macadam I., O'Grady J. \& Ranasinghe R. (2007). Projected Changes in Climatological Forcing for Coastal Erosion in NSW. In. a project undertaken for the Department of Environment and Climate Change NSW CSIRO Marine and Atmospheric Research, Hobart, p. 36.

McInnes K.L., O'Grady J. \& Hubbert G.D. (2009). Modelling Sea Level Extremes from Storm Surges and Wave Setup for Climate Change Assessments in Southeastern Australia. Journal of Coastal Research, Special Issue 56, 1005-1009.

Middelmann-Fernandes M.H. (2010). Flood damage estimation beyond stage-damage functions: an Australian example. Journal of Flood Risk Management, 3, 88-96.

Productivity Commision (2012). Barriers to Effective Climate Change Adaptation, Report No. 59, Final Inquiry Report. In. Australian Productivity Commision Canberra. 